\title{
Reação de cultivares de goiabeiras à Pratylenchus brachyurus
}

\author{
Kerly Cristina Pereira ${ }^{1}$, Pedro Luiz Martins Soares ${ }^{2}$, Jaime Maia dos Santos ${ }^{2}$, \\ Patrícia Aparecida de Carvalho Felisberto ${ }^{2}$
}

${ }^{1}$ Instituto Federal Goiano (IF Goiano), Câmpus Urutaí. Rodovia Geraldo Silva Nascimento, Km 2,5, Zona Rural, Urutaí/GO, $75790-000$, Brasil. ${ }^{2}$ Universidade Estadual Paulista (UNESP), Câmpus de Jaboticabal, Departamento de Fitossanidade, Laboratório de Nematologia. Via de Acesso Prof. Paulo Donato Castellane, s/n, Jaboticabal/SP, 14884-900, Brasil.

Autor para correspondência: Kerly Cristina Pereira (kerlycp2000@yahoo.com.br)

Data de chegada: 13/04/17. Aceito para publicação em: 28/09/18.

$10.1590 / 0100-5405 / 178517$

\section{RESUMO}

Pereira, K.C.; Soares, P.L.M.; Santos, J.M.; Felisberto, P.A.C. Reação de cultivares de goiabeiras à Pratylenchus brachyurus. Summa Phytopathologica, v.44, n.4, p.386-390, 2018.

O nematoide das lesões radiculares (Pratylenchus brachyurus) tem sido encontrado em goiabeiras, todavia, não existem informações na literatura se a referida cultura é uma hospedeira potencial ou se ocorre danos pelo parasitismo do mesmo. O objetivo desse estudo foi avaliar sob condições experimentais de casa de vegetação, o desenvolvimento das cultivares de goiabeiras Paluma, Pedro Sato, Século XXI e Tailandesa quando inoculadas com P. brachyurus. Além disso, plantas inoculadas foram comparadas com não inoculadas. As avaliações de altura, diâmetro do caule, massa fresca das partes aéreas, massa fresca das raízes, população do nematoide nas raízes, bem como o aspecto visual, foram realizadas aos seis e doze meses após a inoculação. Por meio dos resultados obtidos, as cultivares Pedro Sato, Século XXI e Tailandesa não são boas hospedeiras de P. brachyurus, todavia, Paluma é boa hospedeira. A cultivar Tailandesa apresentou o melhor desenvolvimento de diâmetro de colo, massa fresca das partes aéreas e massa fresca de raízes em relação as demais cultivares. A cultivar Paluma é suscetível e intolerante a $P$. brachyurus, Século XXI é resistente e intolerante $a$ P. brachyurus, Pedro Sato é resistente e intolerante a $P$. brachyurus e a cultivar Tailandesa é resistente e tolerante a $P$. brachyurus.

Palavras-chave: Fator de reprodução, hospedabilidade, nematoides das lesões radiculares, Psidium guajava.

\section{ABSTRACT}

Pereira, K.C.; Soares, P.L.M.; Santos, J.M.; Felisberto, P.A.C. Reaction of guava cultivars to Pratylenchus brachyurus. Summa Phytopathologica, v.44, n.4, p.386-390, 2018.

The root lesion nematode (Pratylenchus brachyurus) has been found in guava plants; however, there is no information in the literature about whether the crop is a potential host or is damaged due to parasitism by this nematode. The aim of this study was to evaluate, under greenhouse conditions, the development of the guava tree cultivars Paluma, Pedro Sato, Século XXI and Tailandesa inoculated with P. brachyurus. Furthermore, inoculated plants were compared with non-inoculated ones. Evaluations of height, stem diameter, fresh mass of aerial parts, fresh mass of roots, nematode population in the roots, as well as visual aspect, were performed at six and twelve months after inoculation. According to the obtained results, cultivars Pedro Sato, Século XXI and Tailandesa are not good hosts to P. brachyurus; however, Paluma is a good host. Tailandesa presented the best development of stem diameter, fresh weight of aerial parts and fresh weight of roots, relative to the other cultivars. Paluma is susceptible and intolerant to P. brachyurus; Século XXI is resistant and intolerant to P. brachyurus; Pedro Sato is resistant and intolerant to $P$. brachyurus, and cultivar Tailandesa is resistant and tolerant to P. brachyurus.

Keywords: Reproduction factor, hostability, root lesion nematode, Psidium guajava.

A fruticultura participa na economia brasileira através do valor de exportações e das vendas no mercado interno, sendo responsável por 25 milhões de empregos (9). Está presente em todos os estados brasileiros, contudo o estado de São Paulo destaca-se com $40 \%$ da produção nacional (10). O estado de São Paulo se destaca como o maior produtor de goiabas do Brasil. Segundo dados do Instituto de economia agrícola (IEA) em 2014 (15) produziu 66.736.150 kg de goiaba Paluma para a indústria e $21.219 .425,5 \mathrm{~kg}$ de goiaba para mesa.

$\mathrm{Na}$ cultura da goiaba ocorre danos significativos devido ao ataque de pragas e doenças, a exemplo disto, os nematoides parasitos de plantas ocasionam prejuízos no desenvolvimento e estabelecimento de plantas no pomar, na produção e qualidade de frutos. Esses problemas de ordem fitossanitária, principalmente por ataque de nematoides, vem sendo um fator limitante à cultura (22).

Estudos realizados constataram a existência, até o ano de 2002, de 26 gêneros e 76 espécies de nematoides parasitas de frutíferas (4, 7). As espécies de Pratylenchus são referidas como os nematoides das lesões radiculares nas raízes de hospedeiros $(13,24)$. No Brasil e no mundo, ocupam o segundo lugar em importância econômica, superados, apenas, pelos nematoides de galha (21).

A primeira espécie do gênero Pratylenchus a ser encontrada no Brasil, foi Pratylenchus brachyurus, que é muito difundida atacando culturas de batata (Solanum tuberosum L.), soja (Glycine max L. Merrill) e algodão (Gossypium L.) (16). A referida espécie possui ampla distribuição geográfica e parasita várias culturas como, aveia (Avena sativa L.), milho (Zea mays L.), milheto (Pennisetum glaucum 
L.), girassol (Heliantus annus L.), cana-de-açúcar (Saccharum L.) entre outras (20). Alguns autores relataram a presença desse nematoide parasitando frutíferas. Dinardo-Miranda et al. (8) encontraram $P$. brachyurus parasitando plantas de abacaxi. Esse nematoide foi considerado de grande importância $(11,3)$.

P. brachyurus é um nematoide polífago com hábito endoparasita migrador, portanto normalmente encontrado se deslocando no interior das raízes das plantas. Machos (raramente encontrados na população) e fêmeas são vermiformes, não havendo dimorfismo sexual e reproduzem-se por partenogênese. Frequentemente causa ferimentos nas raízes através dos quais outros organismos patogênicos, penetram, alimentando-se do conteúdo celular, destroem as células e provocam as lesões. As plantas tornam-se pequenas, com ramos finos e podem apresentar clorose ou murcha na estação da seca ou desfolha total quando o ataque é severo (24).

Dias-Arieira et al. (7) estudaram a ocorrência de nematoides em frutíferas cultivadas na região noroeste do Paraná, e observaram abundância relativa $96,7 \%$ de $P$. brachyurus maior em abacaxizeiro enquanto que para as demais frutíferas estudadas, inclusive a goiaba, obteve-se abundância relativa menor $48,7 \%$. O número de nematoides foi mais abundante em abacaxizeiro, com 708 espécimes em $10 \mathrm{~g}$ de raízes e 14,7 espécimes em $10 \mathrm{~g}$ de raízes em goiabeiras. Barbosa et al. (2) constataram alta infestação de P. brachyurus em pomar de goiabeiras em Bauru, SP, com sintomas foliares como os do parasitismo de Meloidogyne enterolobii (26) (sin. M. mayaguensis, 19).

Torres et al. (25) relataram o primeiro assinalamento $P$. brachyurus em meloeiro (Cucumis melo L.) ocorrendo em condições naturais de campo no Brasil, no Pólo Açu-Mossoró, RN. Dias-Arieira et al. (7) relatou a presença de uma frequência relativa do nematoide em raízes de melão de $66,7 \%$ e de $25 \%$ em goiabeiras.

Recentemente, em análises de amostras enviadas pelos produtores, realizadas no Laboratório de Nematologia da UNESP/FCAV, Câmpus de Jaboticabal, foram encontradas populações de P. brachyurus variando de 0 a 132 espécimes em $100 \mathrm{~cm}^{3}$ de solo e 0 a 1120 espécimes em 10 gramas de raízes de pomares de goiabeiras dos municípios de Vista Alegre do Alto, Matão, Guariroba, Taquaritinga, Monte Alto, Itápolis e Arealva, SP.

Não há registros na literatura evidenciando o fator de reprodução maior que 1 nas cultivares de goiabeiras parasitadas por $P$. brachyurus e que esse parasito possa comprometer o desenvolvimento da referida cultura. Diante do exposto, objetivou-se com este trabalho avaliar a reação de cultivares de goiabeiras à $P$. brachyurus.

\section{MATERIAL E MÉTODOS}

O experimento foi conduzido em casa de vegetação situada no Departamento de Fitossanidade da UNESP/FCAV, entre novembro de 2013 a maio de 2014. Nesse período, as médias das temperaturas mínimas e máximas foram 18 e $35^{\circ} \mathrm{C}$, respectivamente.

O inóculo inicial de $P$. brachyurus foi obtido em um pomar de goiabeira Século XXI, localizado no município de Guariroba, SP. As amostras de raízes coletadas foram processadas utilizando a técnica de Coolen \& D'Herde (6) para recuperar a referida espécie de nematoide. Em seguida identificou-se comparando os caracteres morfométricos de fêmeas adultas com os contidos na chave de Castillo \& Vovlas (5).

A referida espécie foi multiplicada in vitro em cilindros de cenoura para obtenção da subpopulação pura, de acordo com a técnica descrita por Gonzaga \& Santos (12), com modificações. Nessa técnica, as cenouras são previamente imersas em hipoclorito de sódio a $0,05 \%$, por 30 minutos. Contudo, no presente estudo a concentração utilizada foi de $0,5 \%$ por 40 minutos. Posteriormente, as cenouras foram seccionadas em 3-4 partes com uma faca flambada, e transferidas para câmara de fluxo laminar, onde foram mergulhadas em álcool etílico comercial $\left(92,8^{\circ} \mathrm{GL}\right)$, flambadas, e, com auxílio de um perfurador, também flambado, foram retirados os cilindros centrais. Individualmente, esses cilindros foram colocados em posição vertical, em vidros previamente vedados com papel alumínio, e autoclavados a $120^{\circ} \mathrm{C}$ com $1 \mathrm{~atm}$ de pressão, por $20 \mathrm{~min}$.

Em vidros do tipo BPI (Boreau of Plant Industries), contendo 200 $\mu \mathrm{L}$ de água destilada autoclavada + tween 80 , foram adicionadas vinte fêmeas da espécie uma a uma. Os nematoides foram axenizados em solução de ampicilina a $0,1 \%$ por 20 minutos. Posteriormente, o excesso da solução foi retirado e adicionou-se água destilada autoclavada + tween 80 , sendo este último procedimento repetido três vezes. Para um litro de água foram adicionadas duas gotas de tween e a autoclavagem se deu a $120^{\circ} \mathrm{C}$ a $1 \mathrm{~atm}$ de pressão por 30 minutos. $O$ tween foi utilizado, por se verificar que muitos nematoides ficavam aderidos às paredes da ponteira, sendo essa, mais uma modificação da técnica citada acima.

Após a axenização, os nematoides foram inoculados nos cilindros de cenoura, com auxílio de uma micropipeta de $200 \mu \mathrm{L}$, os quais foram mantidos em câmaras de crescimento do tipo B.O.D. a temperatura de $27 \pm 1{ }^{\circ} \mathrm{C}$ durante 150 dias. Decorrido este período, os nematoides foram extraídos pela técnica de Coolen \& D'Herde (6). Os indivíduos recuperados foram quantificados sob microscópio fotônico e a suspensão obtida foi ajustada para 100 juvenis, fêmeas e ovos $\mathrm{mL}^{-1}$ para utilização como inóculo.

As mudas de goiabeira Paluma, Pedro Sato, Século XXI e Tailandesa foram adquiridas em viveiros certificados, com cerca de três meses de idade, em sacos de polietileno, contendo o substrato orgânico (Bioplant ${ }^{\mathbb{B}}$ ). O substrato foi irrigado, os sacos removidos e as mudas transplantadas em vasos de plástico de $10 \mathrm{~L}$ de capacidade contendo substrato à base de terra e areia (1:2), autoclavado a $120^{\circ} \mathrm{C}$ e $1 \mathrm{~atm}$ por uma hora.

Após o transplante, as raízes das mudas foram inoculadas com $10 \mathrm{~mL}$ da suspensão contendo 1.000 juvenis, fêmeas e ovos de $P$. brachyurus por planta. Para cada cultivar inoculada com o nematoide, foram mantidas plantas não inoculadas para verificar os possíveis danos.

As plantas foram irrigadas manualmente uma vez ao dia e adubadas com macro e micronutrientes conforme a necessidade. Foram feitas

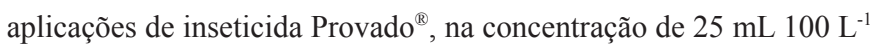
de água para o controle de psilídeos.

As avaliações foram realizadas aos seis e doze meses após a inoculação. As plantas foram removidas dos vasos e posteriormente, foram medidas altura $(\mathrm{H})$, diâmetro do caule no colo $(\mathrm{D})$, massa fresca das partes aéreas (MFPA) e massa fresca das raízes (MFR). As raízes foram acondicionadas em sacos plásticos etiquetados e transportadas para o laboratório. A seguir, foram processadas, seguindo a metodologia de Coolen \& D'Herde (6).

Foram estimadas as populações finais dos nematoides nas raízes com auxílio da câmara de Peters em microscópio fotônico (23). Posteriormente, foi determinado o fator de reprodução $(F R)=$ [população final (PF)/população inicial (PI)]. Cultivares com FR menor que 1 foram consideradas resistentes e aquelas com FR maior ou igual a 1 , suscetíveis (18).

O delineamento foi inteiramente casualisado em esquema fatorial 4x2 (sendo quatro cultivares, com e sem nematoide), com sete repetições para cada cultivar e uma espécie de nematoide, com 
testemunha não inoculada para cada tratamento.

Os dados obtidos foram submetidos a análises de variância através do teste $\mathrm{F}$ e as médias foram comparadas pelo teste de Tukey a 5\% de probabilidade. As variáveis fator de reprodução e número de nematoides foram transformadas em $\log (\mathrm{x}+5)$. Utilizou-se o programa estatístico AgroEstat (1).

\section{RESULTADOS E DISCUSSÃO}

Nas análises de variância e teste de comparação de médias observou-se que, os tratamentos (inoculação com a subpopulação de P. brachyurus) e a testemunha, apresentaram diferenças significativas para o caractere biométrico, massa fresca das raízes apenas aos seis meses (Tabela 1).

Em se tratando das cultivares, puderam-se observar diferenças significativas entre as mesmas aos seis meses da inoculação, entretanto, aos doze meses, somente o diâmetro não foi significativo. Aos seis meses da inoculação, a Tailandesa e a Pedro Sato apresentaram as maiores médias de altura $(\mathrm{H})$ diferindo significativamente da Paluma e Século XXI que apresentaram as menores médias.
Para as variáveis diâmetro (D), massa fresca das partes aéreas (MFPA) e massa fresca das raízes (MFR) a Tailandesa apresentou a maior média diferindo das demais com menores médias, apenas não diferindo da Pedro Sato para o D, MFPA e MFR (Tabela 1).

Aos 12 meses da inoculação, a Século XXI e Paluma continuaram apresentando os menores desenvolvimento na altura diferindo das demais, Pedro Sato e Tailandesa, que apresentaram maiores desenvolvimento. A Tailandesa apresentou a maior média de diâmetro (D) em relação as demais. Também, apresentou a maior média de MFPA, acompanhada de Paluma e Pedro Sato, e a Século XXI que apresentaram a menor média. Em relação a MFR a Tailandesa apresentou a maior média diferindo das outras cultivares avaliadas (Tabela 1 ).

As interações, tratamento $\mathrm{x}$ cultivar foram significativas para as variáveis diâmetro (mm) e massa fresca das partes aéreas (MFPA) aos 12 meses da inoculação (Tabela 1). O desdobramento mostrou que, para o diâmetro, a Tailandesa quando inoculada com $P$. brachyurus apresentou o maior desenvolvimento em relação as demais cultivares e a testemunha não inoculada, mostrando que a referida espécie foi mais agressiva para Século XXI, Pedro Sato e Paluma, evidenciando a tolerância da cultivar Tailandesa ao nematoide (Tabela 2).

Tabela 1. Análise de variância e teste de comparação de médias dos caracteres biométricos de goiabeiras Século XXI, Pedro Sato, Paluma e Tailandesa, aos seis e doze meses após a inoculação com Pratylenchus brachyurus, mantidas em casa-de-vegetação. Jaboticabal, SP.

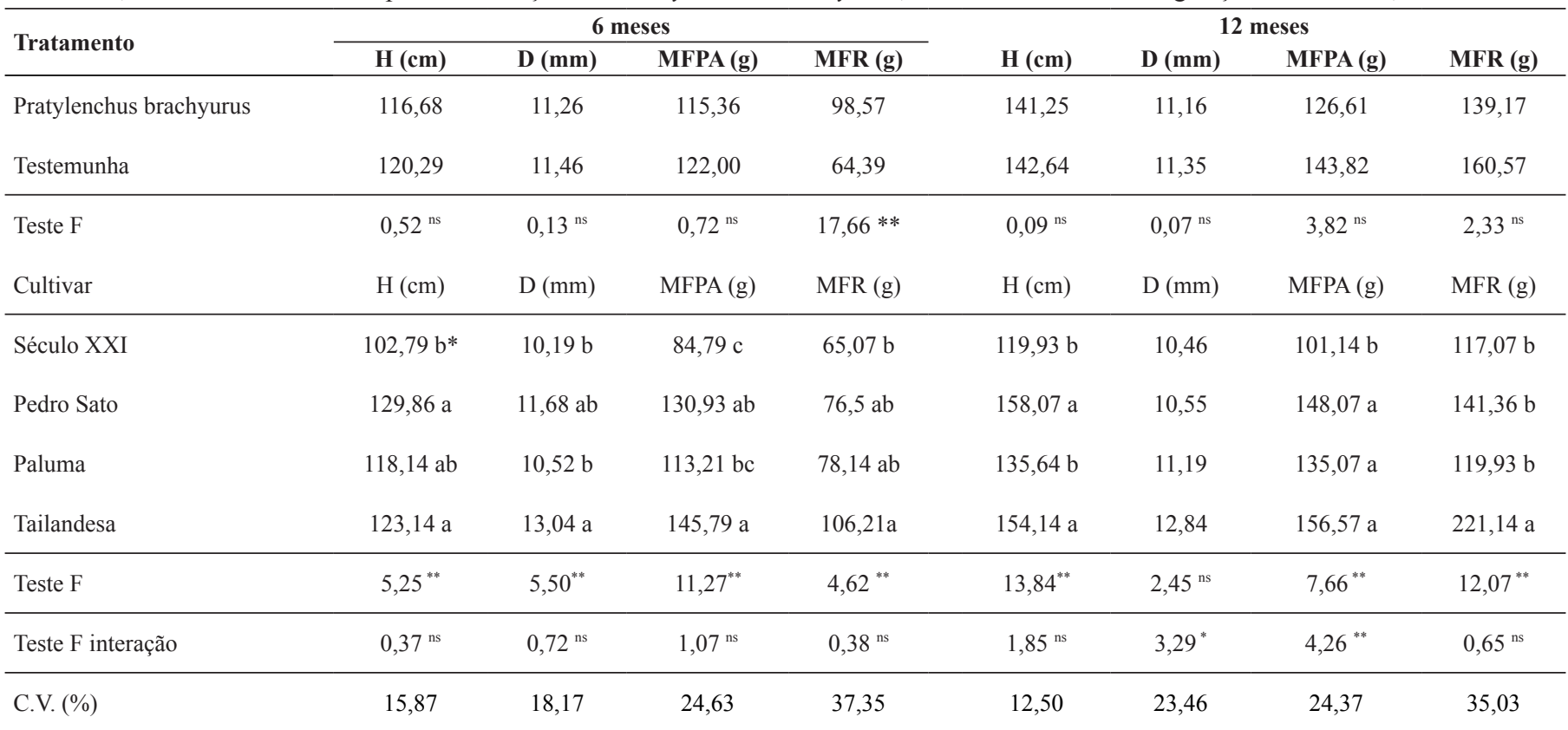

${ }^{\mathrm{x}}$ Letras iguais na coluna não diferem entre si pelo Teste Tukey a $5 \%$ de probabilidade. *Diferença significativa a $5 \%$ de probabilidade; **Diferença significativa a $1 \%$ de probabilidade; ${ }^{\text {ns }}$ Diferença não significativa. H (altura da parte aérea), D (diâmetro), MFPA (massa fresca das partes aéreas) e MFR (massa fresca das raízes).

Tabela 2. Desdobramento das interações entre as cultivares de goiaba e tratamentos compostos por Pratylenchus brachyurus e testemunha para diâmetro (mm) aos doze meses após a inoculação. Jaboticabal, SP.

\begin{tabular}{|c|c|c|c|c|c|}
\hline Tratamento x Cultivar & Século XXI & Pedro Sato & Paluma & Tailandesa & Teste F \\
\hline Pratylenchus brachyurus & $\mathrm{aB}^{\mathrm{x}} 9,44$ & $\mathrm{aB} 10,06$ & $\mathrm{aB} 10,51$ & aA 14,64 & ${ }^{* *} 5,588$ \\
\hline Teste F & ns 2,064 & ns 0,487 & ns 0,904 & ${ }^{*} 6,5$ & \\
\hline
\end{tabular}

${ }^{x}$ Letras iguais, maiúsculas na linha e minúsculas na coluna, não diferem entre si pelo Teste Tukey a $5 \%$ de probabilidade; *Diferença significativa a $5 \%$ de probabilidade; **Diferença significativa a $1 \%$ de probabilidade; ${ }^{\text {ns }}$ Diferença não significativa. 
Para o desdobramento das interações entre tratamentos e cultivares para a MFPA aos 12 meses, observou-se que a Tailandesa e Pedro Sato apresentaram a maior MFPA para a testemunha com o nematoide, em relação a Paluma e Século XXI. Todavia, quando a Tailandesa foi inoculada com $P$. brachyurus apresentou a menor MFPA em relação a testemunha (não inoculada), evidenciando a agressividade do nematoide para esta variável (Tabela 3).

A maior densidade populacional e o fator de reprodução (FR) de P. brachyurus aos seis meses da inoculação foram observados em Tailandesa, não diferindo da cultivar Paluma. Aos doze meses da inoculação os resultados foram diferentes, a Tailandesa apresentou os menores valores diferindo das demais cultivares e a Paluma os maiores valores. Apenas a Paluma apresentou o FR $=3,98$ portanto $>1$, evidenciando a multiplicação do nematoide, sendo uma boa hospedeira e suscetível, enquanto que as demais cultivares apresentaram o FR inferior a 0,95 portanto $<1$, não sendo boas hospedeiras e resistentes ao nematoide (Tabela 4).

Trabalhos realizados com a cultura do algodoeiro com diferentes isolados de $P$. brachyurus mostraram resultados semelhantes ao observado no presente trabalho com goiabeira. Machado et al. (17) e Inomoto et al. (14) observaram duas cultivares de algodoeiro e três isolados de $P$. brachyurus oriundos de diferentes localidades e espécies de plantas e verificaram que não houve crescimento significativo da população de $P$. brachyurus isolada de plantas de quiabeiro (Abelmoschus esculentus Moench.) e milho (Zea mays L.) quando inoculados em plantas de algodoeiro, houve decréscimo da população, não se verificando diferenças significativas entre os isolados e cultivares de algodoeiro com fator de reprodução menor que um.

Dias-Arieira et al. (7), relataram a presença de P. brachyurus em abundância relativa $(14,7)$ em pomares de goiaba no Paraná e Barbosa et al. (2) constataram P. brachyurus em goiabeiras em Bauru, SP.

Dias-Arieira et al. (7) e Barbosa et al. (2) relataram a infecção do $P$. brachyurus em pomares de goiabeiras Paluma e análises realizadas no Laboratório de Nematologia da UNESP/FCAV, Câmpus de Jaboticabal. Encontraram populações de $P$. brachyurus variando de 0 a 132 indivíduos em $100 \mathrm{~cm}^{3}$ de solo e 0 a 1120 indivíduos em 10 gramas de raízes de pomares de goiabeiras dos municípios de Vista Alegre do Alto, Matão, Guariroba, Taquaritinga, Monte Alto, Itápolis e Arealva, no estado de São Paulo.

No presente trabalho notou-se que aos doze meses da inoculação somente a cultivar Paluma foi suscetível ao nematoide, podendo constatar que com o decorrer do tempo essa cultivar, devido a características intrínsecas, poderá ter os sintomas ainda mais acentuados pela ação dos nematoides do que as demais cultivares estudadas.

Ainda, verificou-se resistência das cultivares Paluma, Pedro Sato, Século XXI e Tailandesa ao nematoide aos seis meses. Aos doze meses a cultivar Paluma não mais apresentou essa resistência. Dessa forma, cuidados com a manejo do pomar devem ser sempre tomados, uma vez que esse trabalho além de ter sido realizado em vasos em casade-vegetação, foi por um período de um ano, de certa forma curto, considerando que a goiabeira é uma planta perene. Possivelmente essa espécie de nematoide no decorrer do tempo poderá interferir no desenvolvimento das cultivares de goiabeiras.

A cultivar Século XXI foi mais afetada pelo nematoide para diâmetro e massa fresca da parte aérea, possivelmente por ter o nematoide já se adaptado a essa planta. De fato, isso se justifica pois, a subpopulação utilizada foi extraída de pomar de goiabeiras da cultivar Século XXI. Quanto a população final e fator de reprodução, aos seis meses a Tailandesa mostrou maior densidade populacional, mas ainda assim não apresentou sintomas característicos do parasitismo, possivelmente por apresentar maior quantidade de raízes que as sustentavam. Aos doze meses esse cenário se modificou para a cultivar Paluma e passou a apresentar uma maior densidade populacional e FR $>1$, o que caracteriza-se como suscetível ao nematoide, o que pode ser

Tabela 3. Desdobramento das interações entre as cultivares de goiaba e tratamentos compostos por Pratylenchus brachyurus e testemunha para massa fresca da parte aérea $(\mathrm{g})$ aos doze meses após a inoculação. Jaboticabal, SP.

\begin{tabular}{|c|c|c|c|c|c|}
\hline Tratamento $\mathrm{x}$ Cultivar & Século XXI & Pedro Sato & Paluma & Tailandesa & Teste F \\
\hline Teste F & ns 0,979 & ns 3,391 & ${ }^{\mathrm{ns}} 0,171$ & ${ }^{* *} 12,054$ & \\
\hline
\end{tabular}

${ }^{x}$ etras iguais, maiúsculas na linha e minúsculas na coluna, não diferem entre si pelo Teste Tukey a $5 \%$ de probabilidade; *Diferença significativa a $5 \%$ de probabilidade; **Diferença significativa a $1 \%$ de probabilidade; ${ }^{\text {ns }}$ Diferença não significativa.

Tabela 4. Número de ovos e diferentes estádios de desenvolvimento (população final) e fator de reprodução de Pratylenchus brachyurus em cultivares de goiabeira aos seis e doze meses após a inoculação. Jaboticabal, SP.

\begin{tabular}{|c|c|c|c|c|}
\hline \multirow{2}{*}{ Cultivar } & \multicolumn{2}{|c|}{ População Final } & \multicolumn{2}{|c|}{ Fator de Reprodução } \\
\hline & meses 6 & meses 12 & meses 6 & meses 12 \\
\hline Século XXI & $153,71^{y} b^{x}$ & b 802,29 & b 0,15 & b 0,80 \\
\hline Paluma & ab 274,29 & a 3996,86 & $a b 0,27$ & a 3,98 \\
\hline Tailandesa & a 449,14 & c 257,14 & a 0,45 & b 0,25 \\
\hline Teste F & ${ }^{* *} 5,61$ & ${ }^{* * *} 16,8$ & ${ }^{*} 3,32$ & $* * 15,58$ \\
\hline
\end{tabular}

${ }^{\times}$Letras iguais na coluna não diferem entre si pelo Teste Tukey a $5 \%$ de probabilidade. *Diferença significativa a $5 \%$ de probabilidade; **Diferença significativa a $1 \%$ de probabilidade. ${ }^{y}$ Dados reais e análise efetuada com dados transformados em Log $(x+5) . F R=$ PF/PI $(\mathrm{PI}=5000)$. 
atribuído à características intrísecas.

Por meio dos resultados obtidos, Pedro Sato, Século XXI e Tailandesa não são boas hospedeiras de P. brachyurus, todavia, Paluma é boa hospedeira. A Tailandesa apresentou o melhor desenvolvimento de diâmetro de colo, massa fresca das partes aéreas e massa fresca de raízes em relação as demais cultivares.

Sendo assim, concluiu-se que Paluma é suscetível e intolerante a $P$. brachyurus, Século XXI é resistente e intolerante a P. brachyurus, Pedro Sato é resistente e intolerante a $P$. brachyurus e a cultivar Tailandesa é resistente e tolerante a $P$. brachyurus.

\section{REFERÊNCIAS}

1. Barbosa, J.C.; Maldonado JR, W. AgroEstat: sistema para análises estatísticas de ensaios Agronômicos. Versão 1.1.0.694. Jaboticabal: Funep, 2011.

2. Barbosa, B.F.F.; Souza, G.P.F.; Ruas, A.R.; Santos, J.M.; Barbosa, J.C.; Soares, P.L.M. Controle biológico de Pratylenchus brachyurus em goiabeira com fungos nematófagos, bactérias e produtos orgânicos. In: Congresso Internacional de Nematologia Tropical, Maceió, 2009. Anais. Piracicaba: Sociedade Brasileira de Nematologia, 2009.

3. Calzavara, S.A.; Santos, J.M.; Favoreto, L. Resistência de porta-enxertos cítricos a Pratylenchus jaehni (Nematoda: Pratylenchidae). Nematologia Brasileira, Piracicaba, v.31, n.1, p.7-11. 2007. Disponível em: <http:// docentes.esalq.usp.br/sbn/nbonline/ol\%20311/7-11\%20co.pdf>. Acesso em: 10 fev. 2017.

4. Campos, V.P.; Campos, J.R.; Silva, L.H.C.; Dutra, M.R. Manejo de doenças causadas por nematoides em frutíferas. In: Zambolim, L. (Ed.). Manejo integrado: fruteiras tropicais - doenças e pragas. Viçosa: UFV, 2002. p.185-238.

5. Castillo, P.; Vovlas, N. Nematology Monographs and Perspectives - Pratylenchus (Nematoda, Pratylenchidae): diagnosis, biology, pathogenicity and management. Leiden: Brill Academic Publishers, 2007. 529p.

6. Coolen, W.A.; D'herde, C.J. A method for the quantitative extraction of nematodes from plant tissue. Gembloux: State Agricultural Research Centre, 1972. 77p.

7. Dias-Arieira, C.R.; Furlanetto, C.; Santana, S.M.; Barizão, D.A.O.; Ribeiro, R.C.F.; Formentini, H.M. Fitonematoides associados a frutíferas na região noroeste do Paraná, Brasil. Revista Brasileira de Fruticultura, Jaboticabal, v.32, n.4, p.1064-1071, 2010. DOI: http://dx.doi.org/10.1590/ S0100-29452010005000119

8. Dinardo-Miranda, L.L.; Spironello, A.; Martins, A.L.M. Reação de cultivares de abacaxizeiro a Pratylenchus brachyurus. Nematologia Brasileira, Piracicaba, v.20, n.1, p.1-7, 1996. Disponível em: <http://docentes.esalq. usp.br/sbn/nbonline/ol\%20201/1-7\%20pb.pdf>. Acesso em: 15 mar. 2017.

9. Fachinello, J.C.; Pasa, M.S.; Schmtiz, J.D.; Betemps, D.L. Situação e perspectivas da fruticultura de clima temperado no Brasil. Revista Brasileira de Fruticultura, Jaboticabal, v.33, n.1, p.109-120, 2011. Número especial. DOI: http://dx.doi.org/10.1590/S0100-29452011000500014

10. FAO. FAO Statistical Yearbook: Latin America and the Caribbean Food and
Agriculture. Santiago, 2014. 178p.

11. Ferraz, L.C.C.B.; Zem, A.C. Gênero de Pratylenchus: os nematoides das lesões radiculares. Revisão Anual de Patologia de Plantas, Passo Fundo, v.7, p.157-195, 1999.

12. Gonzaga, V.; Santos, J.M. Estudo comparativo da multiplicação in vitro de seis espécies de Pratylenchus brachyurus em cilindros de cenoura. Nematologia Brasileira, v.34, n.4, p.226-230, 2010. Disponível em: $<\mathrm{http}: / /$ docentes.esalq.usp.br/sbn/nbonline/ol\%20344/226-230\%20co.pdf $>$. Acesso em: 12 fev. 2017

13. Godfrey, G.H. A destructive root disease of pineapples and other plants due to Tylenchus, brachyurus n.sp. Phytopathology, St. Paul, v.19, n.7, p.611-629, 1929 .

14. Inomoto, M.M.; Goulart, A.M.C.; Machado, A.C.Z.; Monteiro, A.R. Effect of population densities of Pratylenchus brachyurus on the growth of cotton plants. Fitopatologia Brasileira, Lavras, v.26, n.2, p.192-196, 2001. DOI: http://dx.doi.org/10.1590/S0100-41582001000200013

15. Instituto de Economia Agrícola. Banco de dados. São Paulo, 2013. Disponível em: <http://www.iea.sp.gov.br/out/ banco/menu.php>. Acesso em: $10 \mathrm{dez} .2015$.

16. Lordello, L.G.E. Nematoides das plantas cultivadas. São Paulo: Nobel, 1988. 314p

17. Machado, A.C.Z.; Beluti, D.B.; Silva, R.S.; Serrano, M.A.S.; Inomoto, M.M Avaliação de danos causados por Pratylenchus brachyurus em algodoeiro. Fitopatologia Brasileira, Lavras, v.31, n.1, p.11-16, 2006. DOI: http:// dx.doi.org/10.1590/S0100-41582006000100002

18. Oostenbrink, M. Major characteristics of the relation between nematodes and plants. Wageningen: Plantenziektenkundige dienst, v.66, p.1-46, 1966.

19. Rammah, A.; Hirschmann, H. Meloidogyne mayaguensis n. sp. (Meloidogynidae), a Root-knot Nematode from Puerto Rico. Journal of Nematology, College Park, v.20, n.1, p.58-69, 1988.

20. Santos, T.F.S. Metodologia de avaliação a Pratylenchus brachyurus e reação de genótipos de soja aos nematoides das galhas e das lesões. 2012. 87f. Dissertação (Mestrado em Engenharia Agrícola)-Instituto de Ciências Agrárias e Tecnológicas, Universidade Federal de Mato Grosso, Rondonópolis.

21. Sasser, J.N.; Freckman, D.W. A world perspective on nematology: the role of the society. In: Veech, J.A.; Dickson, D.W. Vistas on nematology. Hyattiville: Society on Nematologistics, 1987. p.7-14.

22. Somavilla, L.; Gomes, C.B.; Antunes, L.E.C.; Oliveira, R.P.; Carneiro, R.M.D.G. Reação de diferentes frutíferas a Meloidogyne ethiopica. Nematologia Brasileira, Piracicaba, v.33, n.3, p.252-255, 2009. Disponível em: $<$ http://docentes.esalq.usp.br/sbn/nbonline/ol $\% 20333 / 252-255 \% 20$ co. pdf $>$. Acesso em: 5 fev. 2017

23. Southey, J.F. Laboratory methods for work with plant and soil nematodes, London: Ministry of Agriculture, Fishiries and Food, 1970. 148p. (Technical Bulletim, 2).

24. Tihohod, D. Nematologia agrícola aplicada. 2.ed. Jaboticabal: Funep, 2000. 473p.

25. Torres, G.R.C.; Pedrosa, E.M.R.; Siqueira, K.M.S.; Moura, R.M. Pratylenchus brachyurus em Cucumis melo no Brasil. Fitopatologia Brasileira, Lavras, v.29, n.6, p.668-669, 2004. DOI: http://dx.doi.org/10.1590/S010041582004000600013

26. Yang, B.; Eisenback, J.D. Meloidogyne enterolobii n. sp. (Meloidogynidae), a root-knot nematode parasitizing pacara earpod tree in China. Journal of Nematology, v.15, p.381-91, 1983. 